\title{
Cervical spine fractures and rear car seat restraints
}

\author{
B G CONRY* AND C M HALL $\dagger$
}

${ }^{*}$ Department of Diagnostic Radiology, St Bartholomew's Hospital, London, and †Department of Diagnostic Imaging, Hospital for Sick Children, London

SUMMARY Two cases of potentially fatal cervical spine fractures in children who were inadequately restrained by malfunctioning car seat restraints are presented. Adequate parental maintenance of seat restraints and their readjustment when children change from wearing lightweight to thick, heavy clothing are imperative.

Rear car seat restraints are a valuable method of making road travel safer for children. Indeed, the importance of their use has now been emphasised in the Highway Code. ${ }^{1}$ If these devices are not carefully maintained or the straps not tightened adequately then potentially fatal cervical spine fractures can occur. We report two cases in which inadequate restraint allowed such injuries to be sustained.

\section{Case 1}

A 6 year old boy was wearing a rear seat safety harness when the car in which he was travelling was involved in an accident. The straps of the harness had not been adequately tightened and he slipped forwards and downwards in the harness so that the strap rode up round his neck producing forceful hyperextension. He was unconscious for one minute and was initially unable to move his arms or legs.

Examination in hospital showed bruising with the imprint of the harness buckle under his chin, torticollis, and painful limitation of movement. No abnormal neurological signs were present in the limbs but he had slight difficulty with micturition for several weeks after an initial period of urinary retention lasting 24 hours.

Radiographs of the cervical spine showed a fracture at the junction of both pedicles and lateral masses of C2 (Hangman's fracture). He wore a cervical collar for seven months while undertaking normal activities and this resulted in satisfactory healing with no neurological deficit.

\section{Case 2}

A 16 month old boy was sitting in a British Standard 3254 approved car safety seat which had a nonfunctioning crutch strap. As a result of a collision he slid down over the faulty leg strap and under the waist straps, (figs 1a and b). His head toppled forward. On examination he had bruising around his neck and chest, with torticollis and limitation of spontaneous movement. There were no abnormal neurological findings.

Initial radiographs were thought to show no fracture, but on subsequent review a fracture through the odontoid peg with displacement on flexion and some compression of the anterior body of C2 were evident. Treatment with a plaster of Paris Minerva jacket for one month and a brace for a further two months produced satisfactory healing and return of full neck movements.

\section{Discussion}

Children who are not wearing restraints are more likely to be seriously injured in car accidents. ${ }^{2}$ Restraint by harnesses and car safety seats undoubtedly prevent both deaths and injuries, ${ }^{3}$ but such devices are often used incorrectly. ${ }^{4}$

All manufacturers' fitting instructions emphasise the importance of replacing car seat restraints following violent stresses such as road traffic accidents, or if components become worn. Many instructions draw attention to the need for careful individual adjustment of the harness, and some recommend periodic inspection of all anchorage points and harness adjustment devices.

These two cases show that despite this advice parents still fail to adjust the harness adequately and continue to use restraints which are malfunctioning and dangerous. We therefore recommend that all manufacturers explicitly advise periodic inspection by parents of all anchorage points and the harness and locking systems. This may show early abrasion and signs of undue wear which are indications for replacement of the restraint. Parents should also be advised that adjustments to the harness are necessary periodically not only to account for normal growth but also seasonally to account for the changes from light to thick clothing and vice versa.

A design modification to ensure that it is impossible to assemble the locking mechanism without incorporating the crutch strap would be useful and would prevent parents continuing to use unsafe car seats as in case two. In addition, use of the currently 


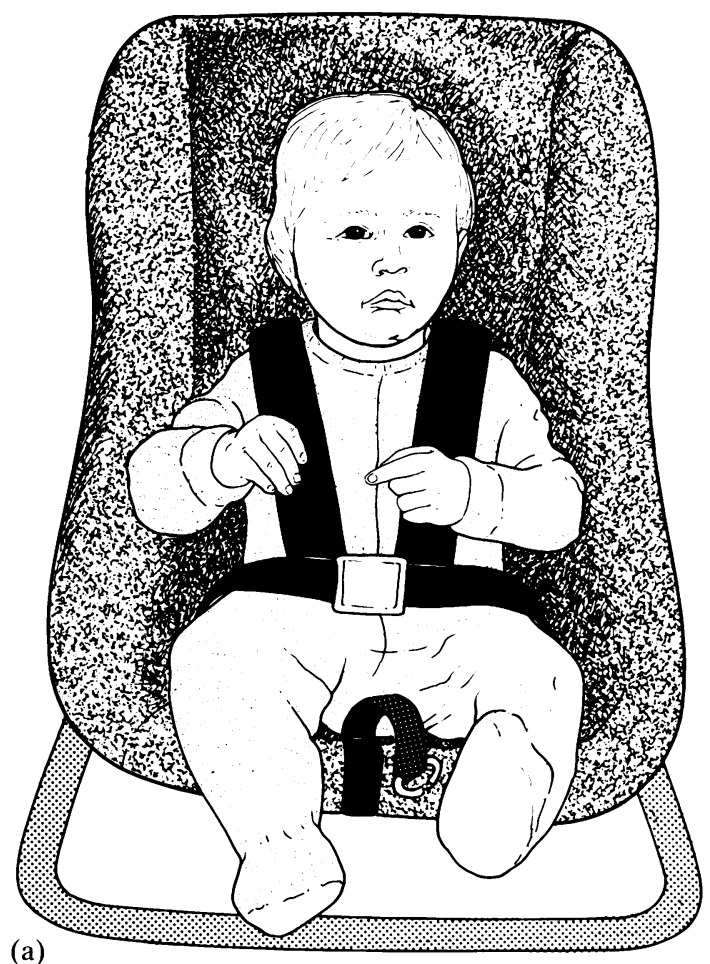

(a)

Figs 1a and b. Position of child in case 2: a) prior to collision (note crutch strap lying free due to malfunction of locking mechanism); b) following collision (having slid forwards and downwards over useless crutch strap, buckle mechanism is forcefully applied to neck and upper chest).

less popular types of car seat design which feature the main lock attached to the crutch strap would have prevented the sliding forward movement shown in figs $1 a$ and $b$.

It is important to emphasise that inadequate parental care and adjustment can transform car seat restraints from a sensible safety precaution into a potentially lethal hazard. We acknowledge that cervical spine fractures in children may be difficult both to diagnose clinically and to see radiologically. ${ }^{5}$ Nevertheless clinicians should be aware of the potential dangers of poorly maintained or malfunctioning restraints and not have a false sense of diagnostic security, thereby dismissing injuries in children because they have been sitting in restraints.

We thank Mr J Fixsen and Mr R Bryant for allowing us to report these cases, Mrs $\mathbf{J}$ Rix for clerical assistance, the department of medical illustration at St Bartholomew's Hospital for the figures, and Ms $\mathrm{N}$ Herrera for typing the manuscript.

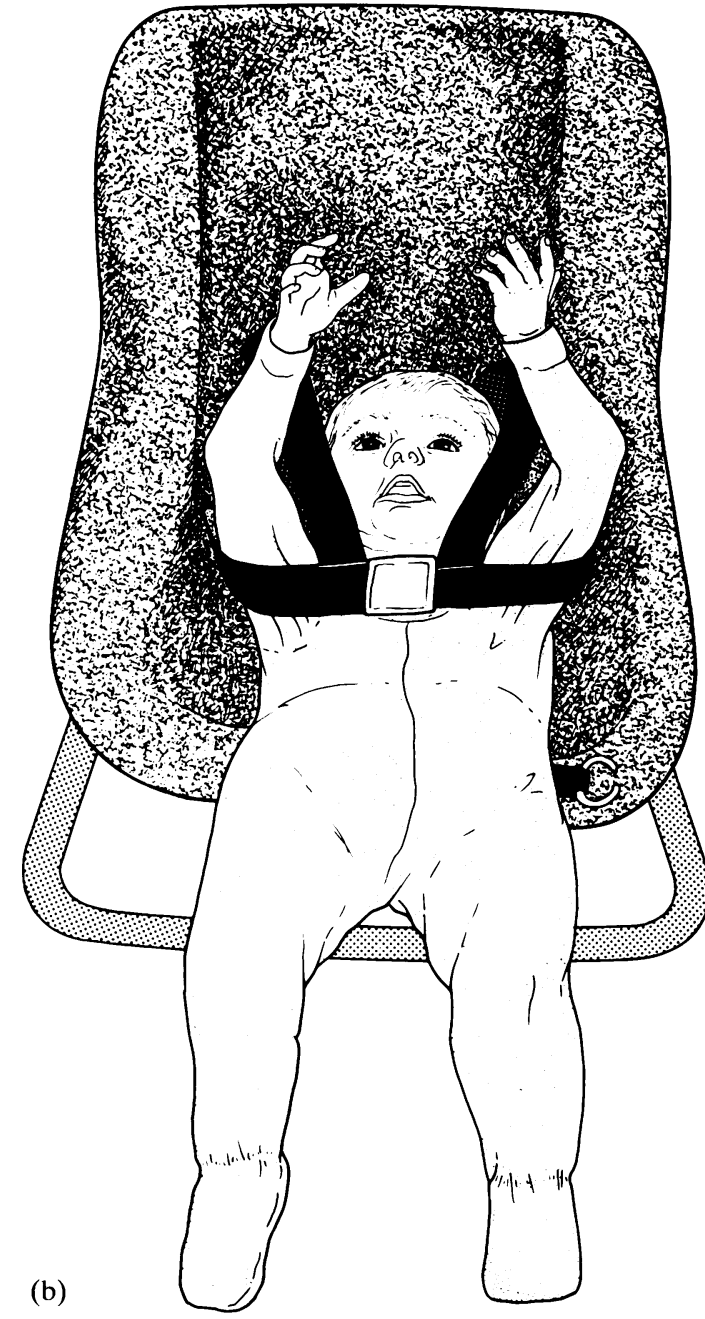

References

1 Department of Transport. The highway code. Revised edition. London: HMSO, 1987;12.

2 Shelnness A, Charles S. Children and car seats. Pediatrics 1986;77:256-8.

3 Avery JG, Hayes HRM. Death and injury to children in cars in Britain. Br Med $J$ 1985;291:515.

4 Williams AF. Observed child restraint use in automobiles. Am J Dis Child 1976;130:1310-7.

5 Bedbrook G. Injuries of the spine. In: Wilson JN, ed. WatsonJones fractures and joint injuries. 6th ed. Edinburgh: Churchill Livingstone, 1982:818-9.

Correspondence to Dr BG Conry, Department of Diagnostic Radiology, Pembury Hospital, Pembury, Tunbridge Wells, Kent TN2 4QJ.

Received 12 June 1987 